\title{
Successful treatment of severe allergic asthma with omalizumab in a girl with DiGeorge syndrome
}

\author{
MILOS JESENAK ${ }^{1}$, MARIA ZELIESKOVA ${ }^{l}$, MIROSLAV REPKO ${ }^{2}$, PETER BANOVCIN ${ }^{l}$ \\ ${ }^{1}$ Department of Pediatrics, Jessenius Faculty of Medicine in Martin, Comenius University in Bratislava, Martin, Slovakia \\ ${ }^{2}$ Department of Pediatrics, Hospital in Poprad, Slovakia
}

\begin{abstract}
DiGeorge syndrome (DGS) is a primary immunodeficiency disease characterized by multiple clinical features, including congenital heart defects, typical facial appearance, hypocalcemia, and immunodeficiency associated to thymic hypoplasia. A subset of patients with DGS may also have contemporary allergic diseases, possibly in the context of $T$ cell dysregulation. Our work presents an unusual case of DGS in coincidence with severe allergic asthma successfully treated by humanized monoclonal anti-IgE antibody, omalizumab. Biological therapy with omalizumab is indicated as an add-on treatment for poorly controlled asthma in patients with severe persistent allergic asthma aged 6 years and above, who meet strict criteria. While data available from clinical trials suggest that omalizumab is generally well-tolerated, a little is known about its efficacy and tolerability in the context of underlying immunodeficiency. We reported for the first time that omalizumab could be safely effective in treatment of severe allergic asthma in patients with DGS, without modification of immunological parameters.
\end{abstract}

Key words: immunodeficiency, DiGeorge syndrome, omalizumab, severe allergic asthma, immune dysregulation.

(Cent Eur J Immunol 2020; 45 (3): 361-363)

\section{Introduction}

DiGeorge syndrome (DGS; 22q11.2 deletion syndrome) is a primary immunodeficiency (PID) resulting from the abnormal development of the third and fourth pharyngeal pouches that belongs to the group of well-defined immunodeficiency syndromes. It is characterized by wide range of clinical features, including congenital heart defects, typical facial appearance, palatal defects, immunodeficiency associated to thymic hypoplasia or aplasia, and hypocalcemia due to hypoparathyroidism [1-3]. Clinical evidence suggests that patients with DGS also have an increased prevalence of allergic and autoimmune diseases, possibly in the context of $\mathrm{T}$ cell dysregulation $[4,5]$.

\section{Case report}

We present a case of 15-year-old female patient with DGS, who also suffered from severe allergic asthma requiring biological treatment with a humanized recombinant monoclonal anti-immunoglobulin E ( $\operatorname{IgE}$ ) antibody, omalizumab. According to the family history, her father and her younger brother have allergic rhinitis (AR) and certain relatives from mother's side suffer from thyre- opathy. However, there are no known cases of severe allergy or immunodeficiency in family. This girl was from a high-risk pregnancy due to gestational diabetes of her mother and she was born on term. While immediate postnatal adaptation has been appropriate, adnate pneumonia developed within two weeks. At the same time, neonatal hypocalcemia with convulsions has been reported. During the neonatal period, she also underwent a cardiosurgery because of congenital heart defect, patent ductus arteriosus. In early infancy, she was diagnosed with bronchial asthma and AR, and since that time, she is regularly followed-up by allergist. Moreover, the diagnosis of autoimmune thyroiditis and subclinical hypoparathyroidism have been established and treated.

Till the age of ten, she was experiencing frequent prolonged respiratory tract infections (including recurrent wheezing attacks). Due to these complaints, she was hospitalized on average five times a year at a pediatric department. During one of the last hospitalizations, detailed physical examination revealed dysmorphic facial appearance, including ocular hypertelorism, antimongoloid slant, telecanthus, short philtrum with fish mouth appearance, low-set hairline, and slightly webbed neck. In addition, 
Table 1. Results of immunological parameters

\begin{tabular}{|c|c|c|c|}
\hline \multicolumn{2}{|c|}{ Parameter } & \multirow{2}{*}{$\begin{array}{c}\begin{array}{c}\text { Test } \\
\text { results }\end{array} \\
16.50\end{array}$} & \multirow{2}{*}{$\begin{array}{c}\begin{array}{c}\text { Normal value } \\
\text { (reference } \\
\text { range) }\end{array} \\
5.52-16.31\end{array}$} \\
\hline Humoral & $\operatorname{IgG}(\mathrm{g} / \mathrm{l})$ & & \\
\hline & $\operatorname{IgA}(\mathrm{g} / \mathrm{l})$ & 2.27 & $0.65-4.21$ \\
\hline & $\operatorname{IgM}(g / 1)$ & 0.35 & $0.3-2.93$ \\
\hline \multirow{10}{*}{$\begin{array}{l}\text { Cellular } \\
\text { immunity }\end{array}$} & CD3+ T lymphocytes (\%) & 60 & $63-80$ \\
\hline & CD3+ T lymphocytes (.109/l) & 913 & $954-2332$ \\
\hline & CD19+ B lymphocytes (\%) & 14 & $12-21$ \\
\hline & CD19+ B lymphocytes (.109/l) & 211 & $173-685$ \\
\hline & CD4+ T lymphocytes (\%) & 29 & $33-52$ \\
\hline & CD4+ T lymphocytes (.109/1) & 441 & $610-1446$ \\
\hline & CD8+ T lymphocytes (\%) & 26 & $19-29$ \\
\hline & CD8+ T lymphocytes (.109/1) & 401 & $282-749$ \\
\hline & CD16+56+ NK cells $(\%)$ & 26 & $4-16$ \\
\hline & CD16+56+ NK cells $(.109 / 1)$ & 400 & $87-504$ \\
\hline
\end{tabular}

Table 2. Evaluation of the effect of treatment with omalizumab after 12 months

\begin{tabular}{lccc}
\hline Parameter & & \multicolumn{1}{c}{$\begin{array}{c}\text { Before } \\
\text { initiation } \\
\text { of omalizumab } \\
\text { treatment }\end{array}$} & $\begin{array}{c}\text { 12 months } \\
\text { after initiation } \\
\text { of omalizumab } \\
\text { treatment }\end{array}$ \\
\hline $\begin{array}{l}\text { Spirometric } \\
\text { indices }\end{array}$ & FEV1 (\%) & 57 & 75 \\
\cline { 2 - 4 } & PEF (\%) & 41 & 54 \\
\cline { 2 - 4 } & FVC (\%) & 74 & 87 \\
\hline Blood & Total IgE (IU/ml) & 122.1 & 56.9 \\
\cline { 2 - 4 } tests & Eosinophils $(\%)$ & 1.9 & 6.9 \\
\cline { 2 - 4 } & Eosinophils $(.109 / 1)$ & 0.1 & 0.3 \\
\hline $\begin{array}{l}\text { Asthma } \\
\text { score (ACT) }\end{array}$ & & 16 & 22 \\
\hline $\begin{array}{l}\text { ACT - asthma control test, FEVI - forced expiratory volume in one second, } \\
\text { FVC-forced vital capacity, IgE-immunoglobulin E, PEF - peak expiratory flow }\end{array}$
\end{tabular}

laboratory evaluation of the immune system indicated immunodeficiency in specific cellular immunity, i.e. mild reduction of total $\mathrm{CD}^{+} \mathrm{T}$ lymphocytes and $\mathrm{CD}^{+} \mathrm{T}_{\mathrm{H}}$ lymphocytes (Table 1). These findings, along with hypoplastic thymus on ultrasound, hypoparathyroidism, neonatal hypocalcemia with convulsions, and congenital heart defect, raised suspicion of primary immunodeficiency disorder. Genetic analysis (fluorescence in situ hybridization) revealed a submicroscopic deletion at chromosome 22 (22q11.2), which is typically associated with DGS.

In the beginning of 2012, our patient visited University Hospital in Martin for the first time. We classified her asthma as moderate, persistent, and partly controlled. At that time, she was treated with combined therapy, consisting of fluticasone, montelukast, and levocetirizine. In order to improve disease control, a fixed combination of fluticasone and salmeterol was administered. In the same year, considering the recurrent tonsillitis and high ASO titer, our patient underwent tonsillectomy. To exclude the diagnosis of pathological gastroesophageal reflux, 24-hour esophageal $\mathrm{pH}$ monitoring was performed and showed physiological results.

One year after the first visit to our center, we noticed that asthma symptoms control in the patient failed. During the last year, she had 3 asthma exacerbations requiring short-term systemic corticosteroid therapy. Moreover, persistent asthma symptoms were disturbing her sleep as well as daily life activities and she often needed a rescue treatment. Spirometry repeatedly showed moderately severe obstruction with positive response to bronchodilator. Skin prick tests and serum specific IgE levels indicated sensitization for perennial allergens (house dust mites, cat and dog epithelia). A total serum IgE concentration was elevated to $122.1 \mathrm{IU} / \mathrm{ml}$. Since comorbidities and non-compliance with treatment were excluded and the inhalation technique was checked, all the criteria for the initiation of biological therapy (anti-IgE monoclonal antibodies, omalizumab) were fulfilled (Table 2). After signing an informed consent by her parents, we initiated the omalizumab treatment.

Consequently, omalizumab has been administered to our patient by subcutaneous injection of $300 \mathrm{mg}$ every 4 weeks in addition to the standard therapy. This therapeutic approach resulted in excellent asthma control, decreased number of respiratory tract infections, and increased quality of the patient's life. After 12 months, we assessed the effectiveness of this therapeutic modality and it has been shown to be efficient. Since no adverse effects have been observed, we decided to continue the treatment with omalizumab up till now.

To date, our patient has been treated by omalizumab for five years and the treatment is well-tolerated. The benefit of this therapy is evaluated every 6 months. Nowadays, she has no clinical symptoms, with improved spirometry parameters and no more exacerbations.

\section{Discussion}

It appears that many types of PID can be associated with predisposition to allergies, although the mechanism underlying this association is not fully understood. Increased frequency of atopic diseases is often seen in humoral PID, such as common variable immunodeficiency, IgA deficiency, and various IgG subclass deficiencies. The association of PID and allergies has been also documented in certain T cell disorders, including Ommen's syndrome and Wiskott-Aldrich syndrome. It is well-known that a subset of patients with DGS might also suffer from 
some form of allergic disease [5]. There is an evidence supporting the hypothesis of homeostatic expansion of peripheral T cell compartment as the compensation of reduced thymic output, resulting to limited $\mathrm{T}$ cell production $[4,6]$. An extreme example of homeostatic proliferation occurs in Ommen's syndrome, where only a small number of $\mathrm{T}$ cells clones proliferate, infiltrate tissues, skew toward a $\mathrm{T}_{\mathrm{H}} 2$ phenotype, and lead to classic atopic manifestations $[4,7]$. It is assumed that atopic features in patients with DGS might be a consequence of the similar process $[4,5]$.

To our knowledge, this is the first reported case of DGS in correlation with severe allergic asthma treated by omalizumab. Biological therapy with omalizumab is indicated as an add-on treatment for poorly controlled asthma in patients with severe persistent allergic asthma aged 6 years and above, who meet strict criteria (Table 2) [8, 9]. Results of several clinical trials have demonstrated that this way of treatment significantly improves asthma symptoms and decreases exacerbation rates as well as reduces doses of standard treatments and increases quality of life [8-11]. Omalizumab is thought to improve asthma control through both anti-allergic and anti-viral immunomodulation [12]. In our patient, shortly after the treatment initiation, we have seen a positive effect that persists up till now.

Several studies have assessed the long-term safety of omalizumab administration in children and in adults, and no serious adverse events have been observed. A recent systematic review of randomized, placebo-controlled clinical trials concluded that a treatment with omalizumab does not result in increased risk of malignancy or hypersensitivity reactions [9]. In addition, a clinical benefit from combination of omalizumab and intravenous immunoglobulin (IVIG) has been confirmed in the case of a patient with common variable immunodeficiency (CVID), with concurrent severe allergic asthma [12]. Moreover, omalizumab therapy showed a remarkable clinical success in the treatment of chronic spontaneous urticaria in an immunodepressed patient for HIV (human immunodeficiency virus) infection and had no effect on peripheral $\mathrm{CD}^{+} \mathrm{T}_{\mathrm{H}}$ counts as well as HIV viral load [13]. The findings of our case report indicate for the first time that anti-IgE therapy with omalizumab could be safe and effective in the treatment of severe allergic asthma in patients with DiGeorge syndrome without modification of immunological parameters. In the light of these facts, anti-IgE therapy with omalizumab presumably do not result in an impairment of immune status, even in patients with underlying immunodeficiency disorder.

\section{Conclusions}

A subset of patients with primary immunodeficiency disorders may also have contemporary allergic diseases, such as bronchial asthma. In our study, we presented an unusual case of partial form of DiGeorge syndrome in correlation with severe allergic asthma, successfully treated with anti-IgE therapy with omalizumab. In spite of underlying immunodeficiency, no deterioration in immunological status has been observed. However, the efficacy and safety of treatment with omalizumab in primary immunodeficiency diseases, including DiGeorge syndrome, require further clinical research.

\section{Acknowledgements}

The study was supported by the project of the Center of Experimental and Clinical Respirology II (ITMS, 26220120034), co-funded from EU sources.

\section{The authors declare no conflict of interest.}

\section{References}

1. Fomin ABF, Pastorino AC, Kim CA, et al. (2010): DiGeorge syndrome: a not so rare disease. Clinics 65: 865-869.

2. Markert LM, Alexieff MJ, Li J, et al. (2004): Complete DiGeorge syndrome: Development of rash, lymphadenopathy, and oligoclonal $\mathrm{T}$ cells in 5 cases. J Allergy Clin Immunol 113: 734-741.

3. Boyarchuk O, Volyanska L, Dmytrash L (2017): Clinical variability of chromosome 22q11.2 deletion syndrome. Cent Eur J Immunol 42: 412-417.

4. Zemble R, Luning Prak E, McDonad K, et al. (2010): Secondary immunologic consequences in chromosome 22q11.2 deletion syndrome (DiGeorge syndrome/velocardiofacial syndrome). Clin Immunol 136: 409-418.

5. Staple L, Andrews T, McDonald-McGinn D, et al. (2005): Allergies in patients with chromosome 22q11.2 deletion syndrome (DiGeorge syndrome/velocardiofacial syndrome) and patients with chronic granulomatous disease. Pediatr Allergy Immunol 16: 226-230.

6. Piliero LM, Sanford AN, McDonald D, et al. (2004): T-cell homeostasis in humans with thymic hypoplasia due to chromosome 22q11.2 deletion syndrome. Blood 103: 1020-1025.

7. Hsu CC, Lee, JY, Chao S (2011): Omenn syndrome: a case report and review of literature. Derm Sinica 29: 50-54.

8. Normansell R, Walker S, Milan SJ, et al. O (2014): Omalizumab for asthma in adults and children. Cochrane Database Syst Rev 2014: CD003559.

9. Rodrigo GJ, Neffen H (2015): Systematic review on the use of omalizumab for the treatment of asthmatic children and adolescents. Pediatr Allergy Immunol 26: 551-556.

10. Campo P, Rodríguez F, Sánchez-García S, et al. (2013): Phenotypes and Endotypes of Uncontrolled Severe Asthma: New Treatments. J Investig Allergol Clin Immunol 23: 76-88.

11. Holgate S, Buhl R, Bousquet J, et al. (2009): The use of omalizumab in the treatment of severe allergic asthma: a clinical experience update. Respir Med 103: 1098-1113.

12. Patel J, Petroni D, Andrew G, et al. (2017): Combination Omalizumab and Intravenous Immunoglobulin (IVIG) as successful treatment of common variable immunodeficiency (CVID) and severe persistent asthma. J Allergy Clin Immunol 139: AB215.

13. Iemoli E, Niero F, Borgonovo L, et al. (2017): Successful Omalizumab treatment in HIV positive patient with chronic spontaneous urticaria: a case report. Eur Ann Allergy Clin Immunol 49: 88-91. 